\title{
A uniportal right upper lobectomy by three-arm robotic-assisted thoracoscopic surgery using the da Vinci (Xi) Surgical System in the treatment of early-stage lung cancer
}

\author{
Yunhai Yang", Liwei Song", Jia Huang, Xinghua Cheng, Qingquan Luo \\ Shanghai Chest Hospital, Shanghai Pulmonary Tumor Medical Center, Shanghai, China \\ \#These authors contributed equally to this work. \\ Correspondence to: Dr. Qingquan Luo; Dr. Xinghua Cheng. Shanghai Chest Hospital, Shanghai Pulmonary Tumor Medical Center, 241 West Huai- \\ Hai Road, Shanghai 200030, China. Email: luoqingquan@hotmail.com; Chengxinghua_001@163.com.
}

\begin{abstract}
Minimally invasive techniques, typified by video-assisted thoracoscopic surgery, are widely practiced in the treatment of thoracic diseases all around the world, and video-assisted thoracoscopic surgery has been recognized as a standard treatment method for early staged lung cancer. Among them, roboticassisted thoracoscopic surgery, which has the advantages of providing a three-dimensional view and better maneuverability, has emerged as a next-generation technique in the field of minimally invasive surgery and is also gaining its popularity with the idea of Enhanced Recovery After Surgery deeply rooted in patients' minds. Up to now, robotic-assisted thoracoscopic surgery usually requires 3 or 4 ports with 1 or 2 additional access incisions. Meanwhile, traditional video-assisted thoracoscopic surgery can now be completed with uniportal method, with less postoperative pain and higher patient satisfaction with respect to the number of incisions in comparison with the multi-port technique. To inform the integration of these new minimally invasive techniques, here, we present a case in which uniportal right upper lobectomy was performed using the $4^{\text {th }}$ generation $d a$ Vinci Robotic Surgical System (Xi). With continuous innovation in robotic minimally invasive techniques and improvements in surgical skills, we believe more patients will benefit from roboticassisted thoracoscopic surgery with single port in the near future.
\end{abstract}

Keywords: Uniportal; robotic-assisted thoracoscopic surgery (RATS); lobectomy

Submitted Feb 22, 2021. Accepted for publication Mar 25, 2021.

doi: $10.21037 /$ tlcr-21-207

View this article at: http://dx.doi.org/10.21037/tlcr-21-207

\section{Introduction}

With the enormous advances in minimally invasive surgery, video-assisted thoracoscopic surgery (VATS) and roboticassisted thoracoscopic surgery (RATS) have become recognized as standard treatments for early-stage lung cancer. Compared with the conventional approach, these minimally invasive techniques have improved postoperative recovery and equivalent oncological efficacy $(1,2)$.

As a quickly evolving, next-generation minimally invasive technique, RATS has increasingly grown in popularity in recent years. The robotic platform has some technical advantages over VATS, including a three-dimensional operative view, intuitive use of the robotic hands, and increased instrument flexibility; therefore, it has the potential to surpass VATS in the handling of more complex cases and may facilitate lymph node dissection (3-6). Currently, RATS requires 3 or 4 ports and 1 or 2 assistive incisions. The uniportal VATS technique, which was first reported in 2004 by Rocco et al. for a wedge resection (7-10), is also appealing to surgeons due to involving potentially less postoperative pain and higher patient satisfaction with respect to the number of incisions (9). Despite respective innovations in these 2 directions, to our knowledge, the completion of RATS using a single incision has never been reported in the literature. With previous experience in both RATS and uniportal VATS (11-15), we report a 
representative video case of right upper lobectomy in the treatment of a subsolid lung nodule (with final pathology of stage I adenocarcinoma) by uniportal RATS using the da Vinci Surgical System (Xi) shown as Video 1 as attached. We present the following article in accordance with the CARE reporting checklist (available at http://dx.doi.org/10.21037/ tlcr-21-207).

\section{Operative techniques}

\section{Clinical vignette}

The presenting case was a 47-year-old man with no

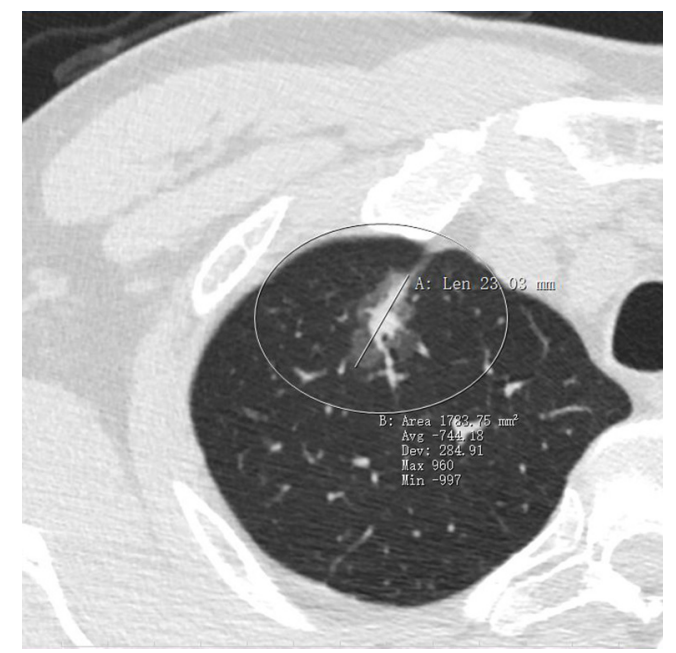

Figure 1 Contrast computed tomography of the presenting case shows the mixed density ground glass nodule in right upper. smoking history. The patient had suffered tuberculosis 35 years previously. Contrast-enhanced chest CT revealed a mixed-density ground-glass nodule in the right upper lobe (Figure 1). The nodule was followed for 3 months and no changes were observed; thus, a right upper lobectomy was scheduled (Figure 1). Preoperative lung function was normal [the forced expiratory volume in 1 second (FEV1) and diffusing capacity for carbon monoxide (DLCO) were $95.1 \%$ and $99.8 \%$, respectively Delete]. The patient had no comorbidities, and his preoperative performance score was 0 .

All procedures performed in studies involving human participants were in accordance with the ethical standards of the institutional and/or national research committee(s) and with the Helsinki Declaration (as revised in 2013). Written informed consent was obtained from the patient.

\section{Operation room setting and incisions (Figure 2)}

After intubation, the patient was placed in the lateral decubitus position. The robot was moved to the cranial side and slightly turned to the back so that the patient cart could be placed parallel to the patient's rib space. A single, 4-cm-long incision was then made at the midaxillary line at the $4^{\text {th }}$ intercostal space. A $30^{\circ}$ camera arm was placed at the upper end of the incision, and subsequently, 2 other instrument arms were placed as shown in Figure 2. There were 3 points of note: (I) arms 1 and 2 were intercrossed
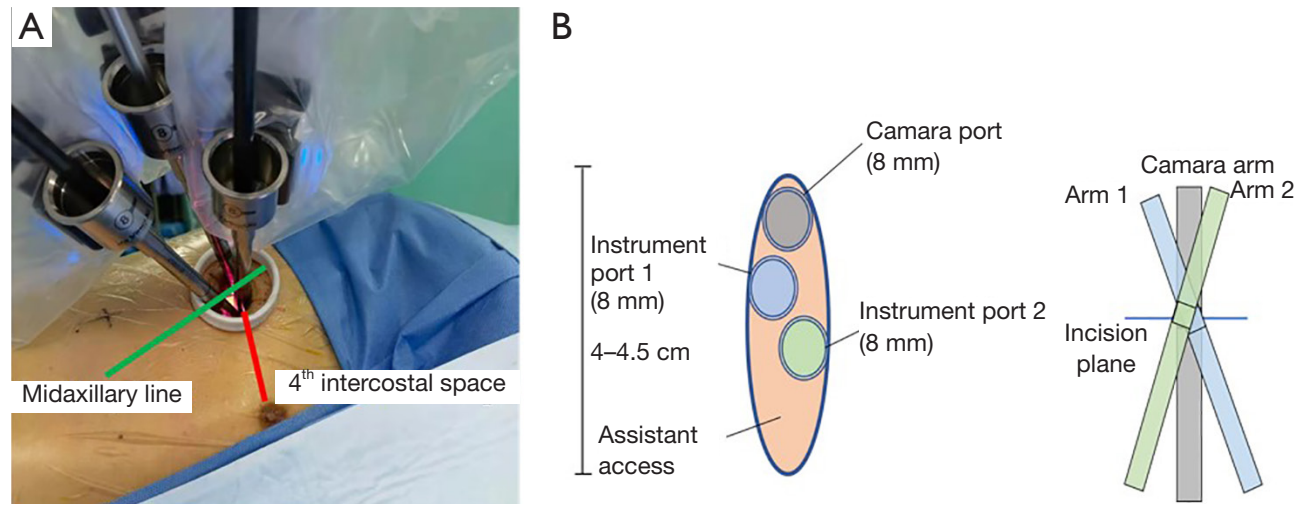

Figure 2 Layout of port in uniportal robotic-assisted thoracoscopic surgery (RATS) with Da Vinci Robotic Surgery System Xi for right upper lobectomy. (A) Uniport position was placed in the 4th intercostal space at the midaxillary line in the surgery of presenting case; (B) the layout of arms in uniport. 


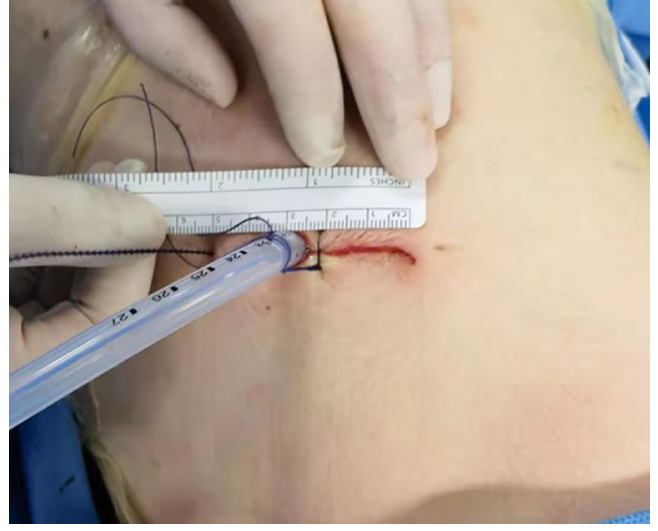

Figure 3 Measurement of the uniport after suture for length about $4 \mathrm{~cm}$.

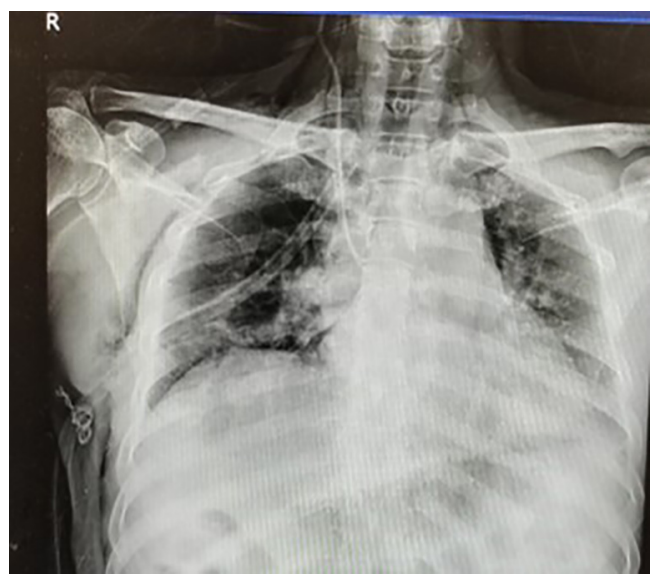

Figure 4 Chest $\mathrm{X}$ radiography showed pulmonary reexpansion the next day after surgery.

inside the chest, and the control of the arms needed to be reset on the operator's console accordingly; (II) the trocars could be installed on the arms before being moved to the incision for positioning; (III) the positioning mark on each trocar needed to be roughly at the level of the patient's skin to avoid instrument collision and compression to the tissue.

After all trocars had been positioned, approximately $1.5 \mathrm{~cm}$ was left at the lower end of the incision for the assistant's access. In total, docking took about 3 minutes. For this operation, the right hand (arm 1) was an electrocautery hook and the left hand (arm 2) was a robotic forceps. To ensure the smoothness of the operation, we chose not to change the distribution of the arms during the procedure. The lung retractor, staplers, clips, and suction were introduced via the uniport by a bedside assistant with previous experience in uniportal VATS.

\section{Surgical steps}

In this case of right upper lobectomy, first, the upper lobe was retracted posteriorly. The dissection was initiated at the anterior hilum to expose the vein and the superior truncus branch. After isolation, the truncus branch was divided using a stapler. The right upper bronchus was then exposed, and lymph nodes of the lower trachea (station 4), hilum (station 10), and the interlobar region (station 11) were removed.

After the dissection of the frontside of the bronchus, the upper lobe was retracted anteriorly. Then, posterior hilar tissue between the intermediate bronchus and the upper lobe bronchus was released to facilitate upper lobe bronchus mobilization. During this process, posterior hilar lymph nodes (station 10) and interlobar lymph nodes (station 11) were removed. To achieve better exposure, the oblique fissure was also be divided with staples or an energetic instrument. The ascending branches of the artery and the upper lobe bronchus were further mobilized and divided by staplers.

After further dissection of the remaining interlobar lymph nodes, the pulmonary vein of the right upper lobe was isolated and divided with a stapler. The lobectomy was completed by dividing the horizontal fissure and collecting the upper lobe in a specimen bag. Due to the relatively low malignancy of the subsolid nodule, sampling of mediastinal lymph nodes of stations $2 \mathrm{R}, 4 \mathrm{R}, 7$, and 8 was systematically carried out. The suture of the surgical incision is shown in Figure 3. The total operation time for the lobectomy and lymph node sampling was approximately 90 minutes.

Postoperative recovery was smooth, and chest $\mathrm{X}$ radiography the following day revealed no abnormality (Figure 4). The patient was discharged 3 days after surgery, and the final pathology reported a lepidic pattern predominant invasive adenocarcinoma measuring $3.2 \mathrm{~cm}$ without lymph node involvement.

\section{Comments}

With better vision, higher maneuverability, and more static movement than VATS, the ability of RATS to perform fine manipulation tasks and lymph node dissection has been greatly improved (16). It has been shown that robotic techniques may be associated with a higher nodal upstaging rate than VATS in patients with clinical stage I non-small 
cell lung cancer $(17,18)$.

Herein, we have presented a case of uniportal RATS performed using the $4^{\text {th }}$ generation $d a$ Vinci Xi Surgical System for right upper lobectomy. The latest robot has 4 interchangeable arms, each including an $8 \mathrm{~mm}$ trocar in which the camera can fit. The size of the trocars is also smaller, thus enabling them to be placed into 1 incision with minimal collision during the surgery. The uniportal technique has been reported to potentially reduce postoperative pain and enhance recovery (19); however, despite its rapid growth in popularity among surgeons who perform VATS, to our knowledge, it has not been adopted in RATS before. Through our efforts to perform RATS with a reduced number of incisions, we hope to combine the advantages of these 2 techniques. With continuous endeavor, we believe this novel technique can bring benefits for our patients and propagate the development of RATS.

\section{Acknowledgments}

We thank anesthetist Xiaying $\mathrm{Xu}$ and nurses Dan Jin, Jiming Yan, and Lingji Shen for their cooperation and contributions in the operation presented.

Funding: This work was supported by funding from the Shanghai Hospital Development Center (SHDC12016113), the National Natural Science Foundation of China (82002427, 82073191), the Shanghai Municipal Health Commission (2018YQ61 and 2019SY047), and the Science and Technology Commission of Shanghai Municipality (18441901500).

\section{Footnote}

Reporting Checklist: The authors have completed the CARE reporting checklist. Available at http://dx.doi.org/10.21037/ tlcr-21-207

Conflicts of Interest: All authors have completed the ICMJE uniform disclosure form (available at http://dx.doi. org/10.21037/tlcr-21-207). The authors have no conflicts of interest to declare.

Ethical Statement: The authors are accountable for all aspects of the work in ensuring that questions related to the accuracy or integrity of any part of the work are appropriately investigated and resolved. All procedures performed in studies involving human participants were in accordance with the ethical standards of the institutional and/or national research committee(s) and with the Helsinki Declaration (as revised in 2013). Written informed consent was obtained from the patient.

Open Access Statement: This is an Open Access article distributed in accordance with the Creative Commons Attribution-NonCommercial-NoDerivs 4.0 International License (CC BY-NC-ND 4.0), which permits the noncommercial replication and distribution of the article with the strict proviso that no changes or edits are made and the original work is properly cited (including links to both the formal publication through the relevant DOI and the license). See: https://creativecommons.org/licenses/by-nc-nd/4.0/.

\section{References}

1. Bendixen M, Jorgensen OD, Kronborg C, et al. Postoperative pain and quality of life after lobectomy via video-assisted thoracoscopic surgery or anterolateral thoracotomy for early stage lung cancer: a randomised controlled trial. Lancet Oncol 2016;17:836-44.

2. Yan TD, Black D, Bannon PG, et al. Systematic review and meta-analysis of randomized and nonrandomized trials on safety and efficacy of video-assisted thoracic surgery lobectomy for early-stage non-small-cell lung cancer. J Clin Oncol 2009;27:2553-62.

3. Veronesi G, Park B, Cerfolio R, et al. Robotic resection of Stage III lung cancer: an international retrospective study. Eur J Cardiothorac Surg 2018;54:912-9.

4. Cerfolio RJ, Ghanim AF, Dylewski M, et al. The longterm survival of robotic lobectomy for non-small cell lung cancer: A multi-institutional study. J Thorac Cardiovasc Surg 2018;155:778-86.

5. Hu J, Chen Y, Dai J, et al. Perioperative outcomes of robot-assisted vs video-assisted and traditional open thoracic surgery for lung cancer: A systematic review and network meta-analysis. Int J Med Robot 2020;16:1-14.

6. Williams AM, Zhao L, Grenda TR, et al. Higher LongTerm Quality of Life Metrics After VATS Lobectomy Compared to Robotic-Assisted Lobectomy. Ann Thorac Surg 2020. [Epub ahead of print]. doi: 10.1016/ j.athoracsur.2020.05.033.

7. Rocco G, Martin-Ucar A, Passera E. Uniportal VATS wedge pulmonary resections. Ann Thorac Surg 2004;77:726-8.

8. Matsuura N, Igai H, Ohsawa F, et al. Uniport vs. multiport video-assisted thoracoscopic surgery for anatomical lung resection-which is less invasive? J Thorac 
Dis 2021;13:244-51.

9. Li T, Xia L, Wang J, et al. Uniportal versus three-port video-assisted thoracoscopic surgery for non-small cell lung cancer: A retrospective study. Thorac Cancer 2021. [Epub ahead of print]. doi: 10.1111/1759-7714.13882.

10. Royo-Crespo I, Vieira A, Ugalde PA. Extended uniportal video-assisted thoracic surgery for lung cancer: is it feasible? J Vis Surg 2018;4:57.

11. Huang J, Li J, Li H, et al. Continuous 389 cases of $\mathrm{Da}$ Vinci robot-assisted thoracoscopic lobectomy in treatment of non-small cell lung cancer: experience in Shanghai Chest Hospital. J Thorac Dis 2018;10:3776-82.

12. Zhao X, Qian L, Lin H, et al. Robot-assisted lobectomy for non-small cell lung cancer in china: initial experience and techniques. J Thorac Dis 2010;2:26-8.

13. Zhou Q, Huang J, Pan F, et al. Operative outcomes and long-term survival of robotic-assisted segmentectomy for stage IA lung cancer compared with video-assisted thoracoscopic segmentectomy. Transl Lung Cancer Res 2020;9:306-15.

14. Huang J, Li C, Li H, et al. Robot-assisted thoracoscopic surgery versus thoracotomy for c-N2 stage NSCLC: short-term outcomes of a randomized trial. Transl Lung

Cite this article as: Yang Y, Song L, Huang J, Cheng X, Luo Q. A uniportal right upper lobectomy by three-arm roboticassisted thoracoscopic surgery using the da Vinci (Xi) Surgical System in the treatment of early-stage lung cancer. Transl Lung Cancer Res 2021;10(3):1571-1575. doi: 10.21037/tlcr-21-207
Cancer Res 2019;8:951-8.

15. Li C, Hu Y, Huang J, et al. Comparison of robotic-assisted lobectomy with video-assisted thoracic surgery for stage IIB-IIIA non-small cell lung cancer. Transl Lung Cancer Res 2019;8:820-8.

16. Hirpara DH, Kidane B. Commentary: VATS, RATS, stats, and some caveats. J Thorac Cardiovasc Surg 2020. [Epub ahead of print]. doi: 10.1016/j.jtcvs.2020.06.072.

17. Wilson JL, Louie BE, Cerfolio RJ, et al. The prevalence of nodal upstaging during robotic lung resection in early stage non-small cell lung cancer. Ann Thorac Surg 2014;97:1901-6; discussion 1906-7.

18. Boffa DJ, Kosinski AS, Paul S, et al. Lymph node evaluation by open or video-assisted approaches in 11,500 anatomic lung cancer resections. Ann Thorac Surg 2012;94:347-53; discussion 353.

19. Magouliotis DE, Fergadi MP, Spiliopoulos K, et al. Uniportal Versus Multiportal Video-Assisted Thoracoscopic Lobectomy for Lung Cancer: An Updated Meta-analysis. Lung 2021;199:43-53.

(English Language Editor: J. Reynolds) 